\title{
Spontaneous haemothorax in a mild haemophiliac
}

\author{
RUDRA RASARET NAM, D. CHA NMUGAM, \\ and C. S I V A T H A A N \\ Colombo General Hospital, Sri Lanka
}

\begin{abstract}
Rasaretnam, R., Chanmugam, D., and Sivathasan, C. (1976). Thorax, 31, 601-604. Spontaneous haemothorax in a mild haemophiliac. Spontaneous haemothorax is a very rare presenting manifestation in haemophilia, only four previous cases being recorded in the English literature. The clinical features and management of such a case by intercostal tube drainage in a previously unrecognized haemophiliac are described.
\end{abstract}

The common manifestations of haemophilia are prolonged and excessive bleeding after minor trauma, spontaneous haemorrhage into the tissues and joints, epistaxis, gastrointestinal haemorrhage, and haematuria. Spontaneous haemothorax is, however, a very rare complication. Freedman, Levine, and Solis-Cohen (1943), when reporting two cases of spontaneous haemothorax in patients with blood dyscrasias, one of whom was a haemophiliac, found only two other cases in the literature, both of whom had been reported before 1900 , but neither suffered from haemophilia. Three further cases have been reported by Pendergrass and Neuhauser (1942), Kay and Kupfer (1957), and Barrett and Israëls (1965), all of whom had been diagnosed as haemophiliacs at an earlier stage. The rarity of the condition prompts us to report a case in which the diagnosis of haemophilia had not already been established.

\section{CASE REPORT}

A 27-year-old man felt a sudden tightening sensation in the left chest just after getting out of bed on 1 November 1975 . It was associated with pain over the left shoulder and breathlessness and became progressively worse, causing him to seek admission to the Colombo General Hospital. There was no history of cough, fever or loss in weight and no history of trauma. On being questioned he gave a history of prolonged bleeding after minor trauma since childhood but had not sought medical advice about it. There were no episodes of spontaneous haemorrhage into the tissues or joints. There had been one previous admission in 1973 for left-sided ureteric colic at which time numerous red cells were present in the urine and no calculi were seen on a plain radiograph of the abdomen.

On examination he was orthopnoeic and clinically anaemic. The trachea was deviated to the right, and there was evidence of a left pleural effusion. A chest radiograph (Fig. 1) revealed a massive left pleural effusion, which on aspiration yielded $500 \mathrm{ml}$ of dark blood, after which he

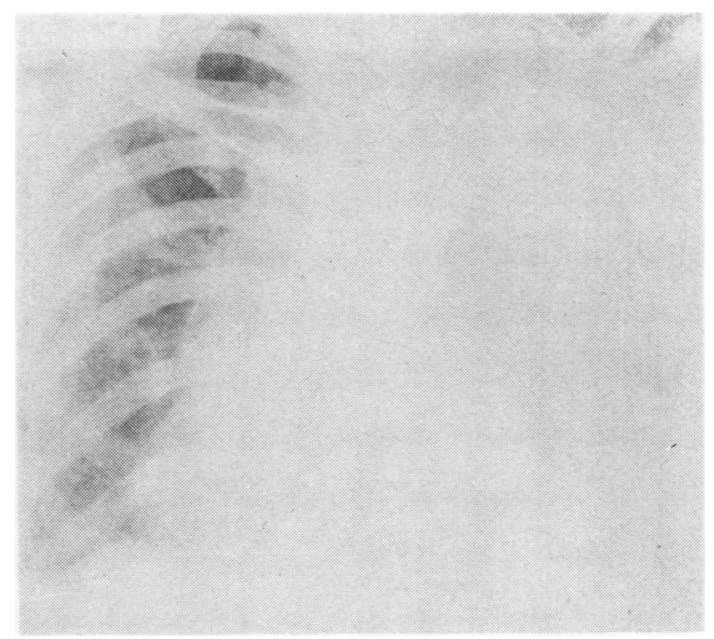

FIG. 1. Chest radiograph on admission on 1 November 1975 showing massive left haemothorax with mediastinal shift to the right. 
was less dyspnoeic. However, the blood pressure, which had been $130 / 80 \mathrm{mmHg}$ on admission, dropped to $100 / 70 \mathrm{mmHg}$ after aspiration. The next day he was again orthopnoeic; tracheal deviation to the right and the signs of a left pleural effusion were still present. He received one pint of bank blood in spite of which his blood pressure was $90 / 60 \mathrm{mmHg}$. On 3 November he was still dyspnoeic and was clinically anaemic. A further $625 \mathrm{ml}$ of blood was aspirated in the morning, and, in view of persistent symptoms and the signs of a haemothorax with mediastinal shift, an intercostal tube was inserted in the afternoon and $250 \mathrm{ml}$ of blood was drained slowly. Soon after insertion of the intercostal tube he developed a moderately large haematoma around the tube. Fresh blood, $1000 \mathrm{ml}$, was transfused. By the following morning a further $800 \mathrm{ml}$ of blood had drained through the intercostal tube. The tube was left in situ for three days during which time another $565 \mathrm{ml}$ of blood drained. On 6 November, although he was symptomatically improved, tracheal deviation persisted and the signs in the left chest were only slightly less than three days previously. A chest radiograph at this time (Fig. 2) showed a residual left haemothorax with mediastinal shift, but in view of the diagnosis of haemophilia, which had now been established, and the dangers of further aspiration, it was decided to treat him conservatively. On 4 January 1976 he was free of symptoms with the trachea now in the

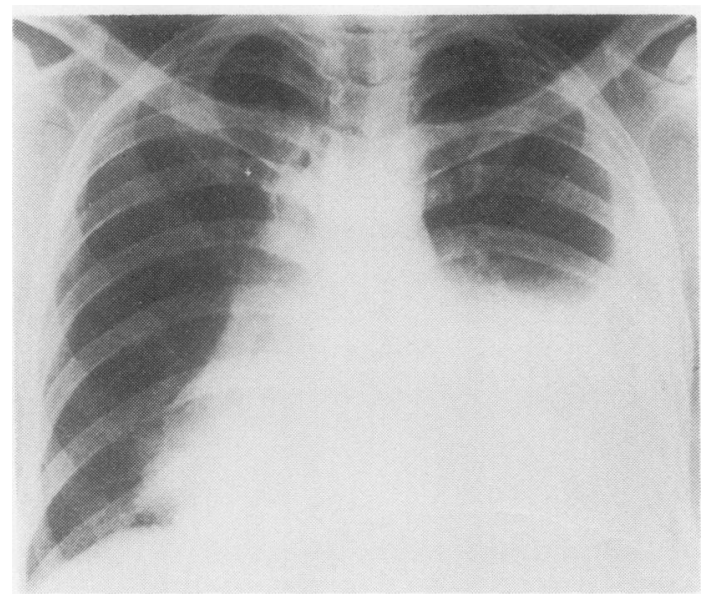

FIG. 2. Chest radiograph soon after removal of the intercostal tube on 6 November 1975. A residual left haemothorax and some mediastinal shift still persist. mid line, and there was only minimal diminution of breath sounds at the left base. A chest radio graph (Fig. 3) confirmed the clinical findings $\overline{\bar{n}}$ Investigations: $\mathrm{Hb} 7.0 \mathrm{~g} / \mathrm{dl}$, PVC $19 \%$, platele count $286 \times 10^{9} / 1$, bleeding time 6 minutes, clot $\frac{0}{7}$ ting time 10 minutes; white cell count $6.8 \times 10^{9} / 1$ क serum bilirubin $18.8 \mu \mathrm{mol} / 1(1.1 \mathrm{mg} \%)$; bloo 5 urea $12.5 \mathrm{mmol} / 1(75 \mathrm{mg} \%)$. Three days after admission the haemoglobin had dropped to $6 \cdot \mathrm{w}_{\mathrm{g}}$ $\mathrm{g} / \mathrm{dl}$ and PCV $18 \%$. The thromboplastin genera tion test was consistent with a deficiency of factor VIII. There was a slow rise in haemoglobin level $\vec{\omega}$ and by the time of his discharge from hospital or 22 December the level was $13.9 \mathrm{~g} / \mathrm{dl}$ and the PClO was $46 \%$. When reviewed in January 1976 the antihaemophilic globulin level was found to be $25 \%$.

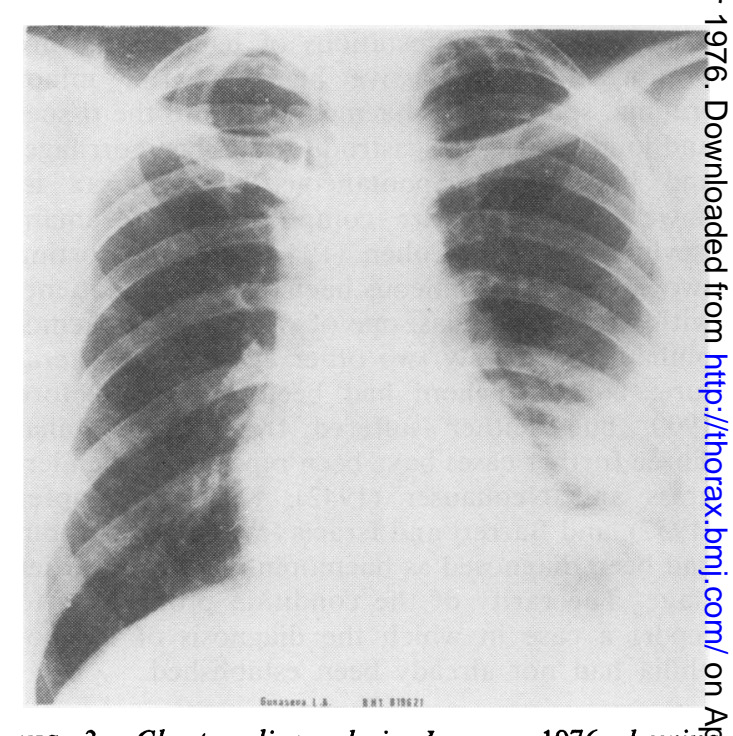

FIG. 3. Chest radiograph in January 1976 showing almost complete resolution of the left haemothora

His father and brother are quite well and have no tendency to prolonged bleeding, but a materna uncle had died as a result of severe haemorrhagळ after an abdominal operation that was mad\& necessary after a fall from an elephant. In spite of numerous requests, only one member of the family, a maternal male cousin, agreed to come to Colombo for investigation and was also found th have a deficiency of factor VIII. 


\section{DISCUSSION}

Spontaneous haemothorax is an unusual clinical state, which is equally rare in the blood dyscrasias. In a search of the English literature we have found only four reported cases of spontaneous haemothorax occurring in haemophilic patients (Pendergrass and Neuhauser, 1942; Freedman et al., 1943; Kay and Kupfer, 1957; Barrett and Israëls, 1965). There are two main problems in the management of these patients; first, the treatment of haemothorax requires evacuation of blood from the pleural cavity to obtain complete expansion of the lung and to prevent the complications of fibrothorax, and, secondly, the management of haemophilia. In the previously reported cases, the diagnosis of haemophilia was already established. In the present case, which is one of the mild variety, although there was a history of prolonged bleeding after minor trauma since childhood, the diagnosis of haemophilia was not made until this admission. The consequences of surgical procedures on haemophiliacs without cover with antihaemophilic globulin (AHG), cryoprecipitate, fresh frozen plasma or fresh blood are well known, and even when this cover has been provided there may still be continued bleeding, as shown by Kay and Kupfer's patient, who began to bleed from the site of the first pleural aspiration seven days later. One of the previous cases was treated conservatively (Barrett and Israëls, 1965) and had a relatively modest haemothorax; the other three were treated by repeated needle aspirations (Pendergrass and Neuhauser, 1942; Freedman et al., 1943; Kay and Kupfer, 1957). Intercostal tube insertion for drainage was eschewed in these cases because of the liability to further haemorrhage. The tendency of these patients to continue bleeding into the pleural cavity is described in the published case reports, and was also evident in our patient, in whom dyspnoea and mediastinal shift persisted and even recurred despite repeated aspirations, and on account of which intercostal tube drainage was thought to be necessary. Fortunately, he was a mild haemophiliac with an AHG content of $25 \%$. However, even in the mild haemophiliacs, in whom the condition may be occult although not entirely free of bleeding episodes, the disastrous consequences of surgical procedures while the condition remains undiagnosed have been documented (Pappas et al., 1964). Mild haemophiliacs usually have more than $5 \%$ of the deficient factor and do not usually give a history of haemarthroses. This is characteristic of the severe form of haemophilia where there is less than $1 \%$ of factor VIII or factor IX. In view of the encouraging reports of treatment of haemarthroses by the early infusion of a new factor VIII concentrate in a dose of 10 units $/ \mathrm{kg}$ (Britton, Harrison, and Abildgaard, 1974), it seems that the current management of haemothorax should include the early and repeated use of factor VIII concentrate together with some form of drainage. Percutaneous aspiration is the least traumatic of the available procedures, but if it is unsuccessful intercostal tube drainage will be required.

Other intrathoracic complications of haemophilia are as uncommon as haemothorax. Haemomediastinum and haemothorax after emesis (Bart, 1972) and following minor trauma (Jivani and Mann, 1970), and haemothorax after minor trauma (Barrett and Israëls, 1965), have been reported. Spontaneous haemothorax has to be differentiated from spontaneous haemopneumothorax which is probably due to the tearing of vascular adhesions when a superficial pleural bleb ruptures (Burke and Salzman, 1959; Barrett and Israëls, 1965).

We wish to thank Mr. Karunasena Gomes f $\simeq$ r the photographs and Miss M. Dullewe for clerical assistance.

\section{REFERENCES}

Barrett, K. E. and Israëls, M. C. G. (1965). Haemothorax in haemophilia. Thorax, $20,416$.

Bart, J. B. (1972). Hemomediastinum and hemothorax in mild hemophilia. Southern Medical Journal, 65, 159.

Britton, M., Harrison, J., and Abildgaard, C. F. (1974). Early treatment of hemophilic hemarthroses with minimal dose of new factor VIII concentrate. Journal of Pediatrics, 85, 245.

Burke, J. F. and Salzman, E. W. (1959). Spontaneous hemo-pneumothorax in a hemophiliac. Journal of the American Medical Association, 169, 1623.

Freedman, P., Levine, S., and Solis-Cohen, L. (1943). Hemothorax in blood dyscrasias. American Journal of Medical Science, 205, 692.

Jivani, S. K. M. and Mann, J. R. (1970). Haemomediastinum in a haemophiliac after minor trauma. Thorax, 25, 372.

Kay, W. R. and Kupfer, H. G. (1957). Spontaneous hemothorax in hemophilia; case report and discussion of the hemophilia syndromes, with remarks on the management of hemothorax. Annals of Internal Medicine, 47, 152. 
Pappas, A. M., Barr, J. S., Salzman, E. W., Britten, A., and Riseborough, E. J. (1964). The problem of unrecognised "mild hemophilia": survival of a patient after disarticulation of the hip. Journal of the American Medical Association, 187, 772.

Pendergrass, E. P. and Neuhauser, E. B. D. (1942). Pleural lesions in hemophilia. American Journal of Roentgenology, 48, 147. Cited by Barrett and Israëls (1965).

Requests for reprints to: R. Rasaretnam, FRCS, 58 Kynsey Road, Colombo-8, Sri Lanka. 